\title{
Necrotic Bone Stimulates Proinflammatory Responses in Macrophages through the Activation of Toll-Like Receptor 4
}

\author{
Naga Suresh Adapala, ${ }^{* \dagger}$ Ryosuke Yamaguchi, ${ }^{* \dagger}$ Matthew Phipps, ${ }^{*}$ Olumide Aruwajoye, ${ }^{*}$ and Harry K.W. Kim ${ }^{*}$
}

From the Center for Excellence in Hip Disorders, * Texas Scottish Rite Hospital for Children, Dallas; and the Department of Orthopedic Surgery, ${ }^{\dagger}$ University of Texas Southwestern Medical Center, Dallas, Texas

\author{
Accepted for publication \\ June 28, 2016. \\ Address correspondence to \\ Harry K.W. Kim, M.D., Texas \\ Scottish Rite Hospital for Chil- \\ dren, 2222 Welborn St., Dallas, \\ TX 75219. E-mail: harry.kim@ \\ tsrh.org.
}

\begin{abstract}
In Legg-Calvé-Perthes disease, loss of blood supply results in ischemic osteonecrosis of the femoral head $(\mathrm{ONFH})$. Generally, macrophages play important roles in inflammatory responses to tissue necrosis, but their role in $\mathrm{ONFH}$ is not known. The purpose of this study was to determine the macrophage-inflammatory responses after $\mathrm{ONFH}$ and the receptor mechanisms involved in sensing the necrotic bone, using a piglet model of Legg-Calvé-Perthes disease. Induction of ONFH resulted in increased numbers of $\mathrm{CD}_{14}{ }^{+}$macrophages in the fibrovascular repair tissue compared with normal, as determined by immunohistochemistry. Quantitative real-time PCR analysis of macrophages isolated by laser capture microdissection showed significantly increased expression of proinflammatory cytokines IL-1 $\beta$, tumor necrosis factor- $\alpha$, and IL- 6 in 0NFH compared with normal. Because Toll-like receptors (TLRs) mediate macrophage-inflammatory responses in other inflammatory conditions, we determined their gene expression in macrophages and found significantly increased levels of TLR4 but not TLR2 and TLR9 in ONFH. Mechanistically, in vitro, bone marrowderived macrophages treated with necrotic bone showed increased extracellular signal-regulated kinases $1 / 2$ and I $\kappa$ kinase- $\alpha$ phosphorylation, increased proliferation, migration, and inflammatory cytokine expression, which were blocked by TLR4 inhibitor, TAK242, and by TLR4 ablation in macrophages using the clustered regularly interspaced short palindromic repeats (CRISPR)/CRISPRassociated protein-9 nuclease method. In conclusion, necrotic bone stimulates macrophageinflammatory responses through TLR4 activation. (Am J Pathol 2016, 186: 2987-2999; http:// dx.doi.org/10.1016/j.ajpath.2016.06.024)
\end{abstract}

Legg-Calvé-Perthes disease (LCPD) is a pediatric hip disorder in which a loss of blood supply to the femoral head results in ischemic osteonecrosis, followed by a development of femoral head deformity and early osteoarthritis. ${ }^{1,2}$ During the repair of the necrotic bone, several features suggestive of chronic inflammatory repair process have been observed both in LCPD patients and in a piglet model of ischemic osteonecrosis of femoral head (ONFH), including excessive resorption of the necrotic bone, delayed new bone formation, and replacement of the necrotic bone by a fibrovascular tissue, which persists over time. ${ }^{2}$ Patients with LCPD have also been shown to have chronic hip synovitis and significantly elevated levels of the proinflammatory cytokine, IL-6, in the synovial fluid. ${ }^{3}$ However, ONFH has not been previously considered to have a chronic inflammatory repair process, and no study has investigated the inflammatory component of the repair process.

Macrophages are known to play a central role in the chronic inflammatory repair processes. ${ }^{4,5}$ After tissue necrosis in conditions such as myocardial infarction, stroke, and chemical injuries to lung and liver, macrophages are known to sense tissue damage using pattern

\footnotetext{
Supported by the Texas Scottish Rite Hospital for Children Research grant (H.K.W.K.).

Disclosures: None declared.
} 
recognition receptors, most commonly Toll-like receptors (TLRs). ${ }^{6-8}$ Among the TLRs, the role of TLR4 is most well characterized. The stimulation of TLR4 results in the activation of myeloid differentiation primary response 88 (Myd88)-extracellular regulated kinase1/2 (ERK1/2), I $\kappa$ kinase (IKK) $\alpha-N F-\kappa B$ pathway and, TIR domaincontaining adapter-inducing interferon (IFN)- $\beta$ (TRIF) and IFN regulatory factor 3 signaling pathways. ${ }^{9}$ Importantly, the activation of $\mathrm{NF}-\kappa \mathrm{B}$ and ERK1/2 signaling pathways result in the gene expression of molecules involved in migration, proliferation, and inflammatory cytokine responses in macrophages ${ }^{10}$ and TRIFdependent signaling results in IFN production and subsequent activation of STAT1-mediated transcription. The involvement of macrophages in the repair process after $\mathrm{ONFH}$ and the receptor mechanisms involved in sensing the ischemic bone damage are unknown. An assessment of the role of macrophages after ONFH would reveal potential mechanisms responsible for chronic inflammation and novel therapeutic approaches to target the inflammatory responses.

Macrophages can perform proinflammatory (causing further tissue damage) or anti-inflammatory (resulting in tissue repair) roles depending on the environment. The predominance of a proinflammatory M1 phenotype [express inducible nitric oxide synthase, IL-12 $\beta$, CD68 and proinflammatory cytokines IL-1 $\beta$, tumor necrosis factor (TNF)- $\alpha$, IL-6, and IFN- $\gamma$ ] or an anti-inflammatory M2 phenotype (express Arg1, Ym1, CD163 and antiinflammatory cytokines IL-4, IL-10) has been suggested to correlate with further tissue damage or resolution of inflammation, respectively. ${ }^{11,12}$ After ONFH, it is not known whether the macrophages in the repair environment show a proinflammatory M1 or an anti-inflammatory M2 phenotype.

The purpose of this study was to determine the inflammatory response of macrophages to the necrotic bone and the pattern recognition receptors involved in the sensing of necrotic bone using a well-established piglet model of ONFH. ${ }^{13-15}$ We hypothesized that after ONFH, necrotic bone stimulates the proliferation, migration, and inflammatory cytokine expression in macrophages and that macrophages in necrotic repair environment have a proinflammatory phenotype.

\section{Materials and Methods}

\section{Animals}

The animal study was approved by Institutional Animal Care and Use Committee at University of Texas Southwestern Medical Center. Yorkshire piglets (6 to 8 weeks old) were obtained from a local breeder and were housed at the University of Texas Southwestern animal care facility. A total of 20 piglets were used in this study as described below.

\section{Induction of $\mathrm{ONFH}$}

ONFH was induced in the right femoral head $(n=12$ piglets) by placing a suture ligature tightly around the femoral neck and by transection of the ligamentum teres, as described previously. ${ }^{13-15}$ The left femoral head was unoperated and served as the control group. The piglets were sacrificed, and samples were collected at 8 weeks after the surgery, a time point at which there is a persistence of fibrovascular repair tissue in the femoral head and a severe collapse of the femoral head similar to that observed in patients with LCPD. ${ }^{13-15}$ The number of macrophages and levels of gene expression of inflammatory cytokines were used as primary outcome measures. For micro computed tomography (CT) imaging, histology, and immunohistochemistry ( $n=6$ piglets), for flow cytometry, frozen sectioning, and laser capture microdissection (LCM) and the preparation of necrotic bone material in the osteonecrosis group ( $n=6$ piglets), the indicated number of animals were used. For the sham operation group ( $n=3$ piglets), the femoral neck was exposed but no ligation or transection was performed. Bone marrow was collected from the tibia of unoperated piglets ( $n=5$ piglets) for the generation of macrophages in vitro.

\section{Micro CT Imaging}

The femoral heads were bisected coronally and gross images were taken. The bisected femoral heads were fixed in $10 \%$ neutral buffered formalin. A micro CT scanning was performed at $100 \mathrm{kV}$ and $100 \mu \mathrm{A}$ (SkyScan 1172; SkyScan, Kontich, Belgium) at a set resolution of $26.6 \mu \mathrm{m}$ per pixel, and rotation steps were 0.80 degrees over a 180-degree range. The three-dimensional reconstruction and visualization were performed using BrukerMicroCT softwares NRecon Reconstruction version 1.6.8 and CT Vox version 2.6.0, respectively (Kartuizersweg, Kontich, Belgium).

\section{Histology and Immunohistochemistry}

Femoral heads were decalcified using 14\% EDTA, and embedded in paraffin. Three micron-thick sections were cut using a microtome (Shandon Finesse; Thermo Scientific, Waltham, MA). Hematoxylin and eosin staining was performed using a standard method. For immunohistochemistry, paraffin sections were processed with trypsin digestion, inhibition of endogenous peroxidase activity, and blocking with goat serum (Dako, Carpentaria, CA). Frozen sections for immunohistochemistry or LCM were prepared at $10 \mu \mathrm{m}$ thickness using a cryostat (MICROM HM560; Thermo Scientific). Mouse monoclonal antibodies at 1:100 or 1:200 dilutions were used against CD14 (MIL-2) (AbD Serotec, Raleigh, NC). Rabbit polyclonal antibodies were used against IL-1 $\beta$ (ab9722), TNF- $\alpha$ (ab6671), IL-6 (ab6672), and TLR4 (HTA-125) (Abcam, Cambridge, MA). As secondary antibodies, a goat anti-mouse IgG 
biotinylated antibody and a goat anti-rabbit IgG biotinylated antibody (Millipore, Billerica, MA) diluted in phosphatebuffered saline (dilution 1:500) were used, and the staining was visualized with, 3,3'-diaminobenzidine tetrahydrochloride (Sigma-Aldrich, St. Louis, MO) for 10 minutes before brief counterstaining with hematoxylin (Invitrogen, Carlsbad, CA). Mouse and rabbit IgG were used as isotype controls (Abcam). The numbers of macrophages were quantitated using ImageJ software version $1.51 \mathrm{f}(\mathrm{NIH}$, Bethesda, MD), using 20 images per section, captured at $\times 20$ magnification with a Nikon Eclipse E800M microscope (Nikon, Tokyo, Japan).

\section{Flow Cytometry}

Femoral head samples were digested with collagenase (Thermo Scientific; $2 \mathrm{mg} / \mathrm{mL}$ ) and hyaluronidase (SigmaAldrich; $2 \mathrm{mg} / \mathrm{mL}$ ). The red blood cells were lysed using ACK $(0.15 \mathrm{~mol} / \mathrm{L}$ ammonium chloride, $1 \mathrm{~mol} / \mathrm{L}$ potassium bicarbonate, $0.1 \mathrm{~mol} / \mathrm{L}$ EDTA) lysis buffer, washed, and single-cell suspensions were labeled using a porcine CD14-fluorescein isothiocyanate (MIL-2) antibody (GeneTex, Irvine, CA) after FcR blockade (Miltenyi Biotec, San Diego, CA), in the fluorescence-activated cell sorting staining medium containing $1 \times$ Hanks' balanced salt solution, $0.01 \mathrm{~mol} / \mathrm{L}$ HEPES (pH 7.4) and $2 \%$ fetal calf serum (Gibco, Waltham, MA). 7-Aminoactinomycin D-positive dead cells were identified and excluded before analysis. Flow cytometry was performed using BD-FACS LSRII (BD Biosciences, San Jose, CA), and the data were analyzed using FlowJo software version 9 (Tree Star Inc., Ashland, $\mathrm{OR})$.

\section{LCM}

LCM was performed on frozen sections. To facilitate the visualization of macrophages, nonspecific esterase (NSE) staining was performed. ${ }^{16}$ NSE-positive cells were then harvested by the LCM method ${ }^{17}$ under strict RNase-free conditions using an ArcturusXT LCM System (Life Technologies, Carlsbad, CA). Low-power laser conditions were used $(70 \mathrm{~mW}, 15$ milliseconds, spot size of $25 \mu \mathrm{m}$ ). Approximately 500 NSE-positive cells were obtained from the frozen sections for each animal $(n=6$ piglets $)$ and immediately preserved at $-80^{\circ} \mathrm{C}$ in lysis buffer (ArcturusPicoPure Frozen RNA isolation kit; Life Technologies) until further use.

\section{LCM RNA Preparation, Linear Amplification, and Quantitative Real-Time PCR}

RNA isolation was performed according to the manufacturer's protocol for the ArcturusPicoPure Frozen RNA isolation kit. The quantity of the RNA was assessed by Nanodrop ND-1000 spectrophotometer (NanoDrop, Wilmington, DE), with a typical RNA yield of 0.9 to $1.7 \mathrm{ng} / \mathrm{mL}$ from each pig sample, with 260:280 ratios in the range of 1.5 to 2.0. The RNA integrity number was assessed using an Agilent Bioanalyzer (Santa Clara, CA) (Supplemental Figure S1 and Supplemental Table S1). An analysis of the mRNA expression in LCM samples was performed in the following three steps: i) reverse transcription used $10 \mathrm{ng}$ of RNA, RT reaction was performed using Superscript First Strand Synthesis System for RT-PCR (Invitrogen) in a $30-\mu \mathrm{L}$ reaction volume; ii) linear amplification used a LCM primer pool for genes of interest, a linear amplification was performed using $12 \mu \mathrm{L}$ of cDNA from RT reaction, using a Platinum Taq polymerase (Life Technologies); and iii) quantitative RT-PCR used a 1:10 dilution of linear amplification product from step 2 for quantitative RT-PCR reaction, using forward and reverse LCM primers for each gene of interest using a Bio-Rad iTaq Universal SYBR Green Supermix (Bio-Rad Laboratories, Hercules, CA) and Applied Biosystems 7500 Real Time PCR System (Thermo Scientific). Data analysis was performed using the deltadelta CT method. The sequence information for the LCMspecific primers used in this study is shown in Table 1.

\section{Immunofluorescence Staining and Fluorescence Microscopy}

Frozen sections or macrophages cultured on glass coverslips were treated with appropriate primary antibodies as mentioned above, followed by incubation in a mix of a goat anti-mouse $\operatorname{IgG} 2^{0}$ antibody conjugated with Alexa Fluor 488 (dilution 1:200) and a goat anti-rabbit IgG $2^{0}$ antibody conjugated with Alexa Fluor 594 (dilution 1:500; Thermo Scientific). This step was followed by a nuclear staining using DAPI (Vector Laboratories, Burlingame, CA). Stained sections were examined using an Axioskop2 MOT microscope (Carl Zeiss, Oberkochen, Germany).

\section{Preparation of Normal Bone and Necrotic Bone for in Vitro Treatment Studies}

Normal and necrotic bone were curetted from proximal femoral epiphysis under aseptic, strictly sterile conditions using endotoxin-free equipment and sterile saline containing protease inhibitors (Sigma-Aldrich). The bone samples were sectioned into pieces to release cells and tissue fluid into the saline suspension. The samples were centrifuged at $2000 \times g$ for 5 minutes at $4^{\circ} \mathrm{C}$. The supernatant fraction (necrotic bone fluid) that may contain soluble proteins such as inflammatory cytokines was separated from the bone sediment fraction (necrotic bone). The necrotic bone was pulverized into a powder using liquid nitrogen and re-suspended in saline containing protease inhibitors. Both the supernatant and sediment fractions from the normal and necrotic bone samples were tested for endotoxin contamination, which can activate TLRs. The endotoxin levels were undetectable by a limulus amebocyte lysate test (below 0.1 endotoxin units/mL; Pierce, Waltham, MA). 
Table 1 Sequence Information for the Sus scrofa Laser Capture Microdissection Primers Used in the Linear Amplification and Quantitative RT-PCR

\begin{tabular}{|c|c|c|}
\hline Gene & Forward primer & Reverse primer \\
\hline NOS2 & $5^{\prime}-$ TGAATCTGGGTGAAGAGCCC-3' & 5'-TCATCCTGTGTTACTGGAACAAT-3' \\
\hline$I L-12 \beta$ & $5^{\prime}$-GCATTGGGGTACCAGTCCAA-3' & $5^{\prime}$-GGAGCTTATAGCCTGACCCC-3' \\
\hline $\operatorname{Arg} 1$ & $5^{\prime}-\mathrm{AGCCCAGCAAGTTCATACCT-3^{ \prime }}$ & $5^{\prime}$-ACCAGCCAGCTTTGTCAGAT-3' \\
\hline$Y m 1$ & $5^{\prime}$-GGGTCCTCAGCCACACATAC- $3^{\prime}$ & $5^{\prime}$-CTCTGTGGCCTCTCCTCAAC-3' \\
\hline CD163 & $5^{\prime}$-CACGAGTCCCACCTTTCACT-3' & 5'-GTGTATCTTGAGCAGACTACGCC-3' \\
\hline$I L-6$ & 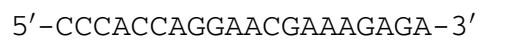 & $5^{\prime}-$ TGAAGGCGCTTGTGGAGAG- $3^{\prime}$ \\
\hline$I F N-\gamma$ & 5'-TCAGCTTTGCGTGACTTTGTG-3' & $5^{\prime}-$ TGAGGTACTTGCATTAAAATAGTCC-3' \\
\hline$I L-4$ & $5^{\prime}-\mathrm{ACACAAGTGCGACATCACCT-3^{ \prime }}$ & 5'-TGCACGAGTTCTTTCTCGCT-3' \\
\hline$I L-10$ & 5'-CGGCCCAGTGAAGAGTTTCT-3' & $5^{\prime}$-GGCAACCCAGGTAACCCTTA-3' \\
\hline$T L R 2$ & 5'-CGGTGTGCTGCAAGGTCAA-3' & $5^{\prime}$-CAATCCCCAAGACCCATGCT-3' \\
\hline
\end{tabular}

Porcine specific exon-exon spanning laser capture microdissection primers were designed using National Center for Biotechnology Information primer design resources (https://www.ncbi.nlm.nih.gov/tools/primer-blast).

\section{In Vitro Studies of Bone Marrow-Derived Macrophages}

To obtain pig macrophages in culture, total bone marrow cells were cultured in a petri dish in the presence of $20 \mathrm{ng} /$ $\mathrm{mL}$ recombinant human macrophage colony-stimulating factor (R\&D Systems, Minneapolis, MN) in $\alpha$-minimum essential medium containing $10 \%$ fetal bovine serum (Sigma-Aldrich), $1 \%$ penicillin-streptomycin $10,000 \mathrm{U} / \mathrm{mL}$ (Gibco, Waltham, MA).

Macrophages were exposed to the necrotic bone fluid or the necrotic bone or normal bone. For the in vitro mRNA expression analysis, total RNA was isolated at 6 or 24 hours. To determine the effect of TLR4 inhibition, macrophages were treated with $100 \mu \mathrm{g} / \mathrm{mL}$ necrotic bone in the presence or absence of TLR4 inhibitor TAK242 (Calbiochem, Temecula, CA). The $\mathrm{EC}_{50}$ of the inhibitor TAK242 was determined in a dose-response study using the Transwell migration assay (Supplemental Figure S2).

For migration assay, macrophages were allowed to migrate for 4 hours in a $5-\mu$ Transwell plate (Corning, Corning, NY) according to the manufacturer's instructions. The percentages of seeded cells that have migrated to the lower surface were determined, and the data are expressed as fold difference compared with basal migration in $\alpha$-minimum essential medium only (ie, no stimulation). For proliferation assay, macrophages were plated in quadruplicates in a 96-well tissue culture plate at a density of $2 \times 10^{4}$ cells per well and allowed to proliferate for 48 hours. The proliferation assay was performed using CellTiter 96 AQueous One Solution (Promega, Madison, WI) according to the manufacturer's instructions.

For Western blot analysis, macrophages were serumstarved for 60 minutes, followed by stimulation with necrotic bone $(100 \mu \mathrm{g} / \mathrm{mL})$. For inhibitor studies, cells were treated with TLR4 inhibitor TAK242 for 30 minutes, which were replenished during the treatment with necrotic bone for an additional 30 minutes. For clustered regularly interspaced short palindromic repeats (CRISPR)-CRISPR-associated protein-9 endonuclease (Cas9) TLR4 study, total bone marrow was cultured on petri dish in the presence of MSCF $(20 \mathrm{ng} / \mathrm{mL})$ for 48 hours. The adherent macrophage precursor cells were transfected with either the control or TLR4 CRISPR-Cas9 plasmids as per the manufacturer's instructions (Santa Cruz Biotechnology, Dallas, TX). The transfection efficiency was determined by green fluorescent protein signal. After 48 hours, macrophages were serumstarved and were stimulated as described above for Western blot experiments using TAK242. The deletion of TLR4 by CRISPR-Cas9 TLR4 but not by control plasmid was confirmed by Western blot analysis.

Total cell lysates were probed for phosphorylated and total forms of ERK1/2 (Cell Signaling Technology, Danvers, MA), IKK $\alpha$ (Thermo Scientific), or STAT1 (Santa Cruz Biotechnology) using specific antibodies. For the determination of TLR4 protein expression, macrophages were cultured in the presence of normal or necrotic bone for 24 hours, followed by Western blot analysis using TLR antibody (Abcam) and $\beta$-actin (Cell Signaling Technology) antibody. The scanning and quantitation of blots was performed using a LICOR imaging system (Lincoln, NE).

\section{Statistical Analysis}

For the determination of the piglet sample size, an $\alpha$ of 0.05 and at least $80 \%$ power to detect a difference of 1.8 SDs by a standard $t$-test were used. Statistical analyses were performed using GraphPad Prism software version 6.0 (GraphPad Software Inc., La Jolla, CA). For 
comparison of two groups, a Student's $t$-test and for more than two groups, analysis of variance and Tukey's post hoc test were used. $P<0.05$ was considered statistically significant.

\section{Results}

Repair Tissue in the Necrotic Femoral Head Contains Significantly Increased Number of Proinflammatory M1 Macrophages

A severe flattening deformity of the necrotic femoral head was observed at 8 weeks after the induction of ONFH ( $n=6$ piglets) (Figure 1A). Bisection of the femoral heads revealed a fibrovascular tissue in the necrotic femoral heads (Figure 1A), and extensive bone loss was observed by micro CT imaging (Figure 1A). Histologic analysis using hematoxylin and eosin staining showed a fibrovascular repair tissue invading the necrotic marrow space and remnants of the necrotic trabecular bone (Figure 1B).

For the detection of macrophages, an immunohistochemistry was performed using the porcine CD14 antibody ${ }^{18}$ (Figure 1C). In the fibrovascular tissue, macrophages were mainly present around small blood vessels. The quantitation of the number of macrophages showed a 4.2-fold increase in the number of $\mathrm{CD}_{1} 4^{+}$macrophages $(P=0.007)$ in the repair tissue compared with normal bone (Figure 1D). The increase in the number of macrophages
A

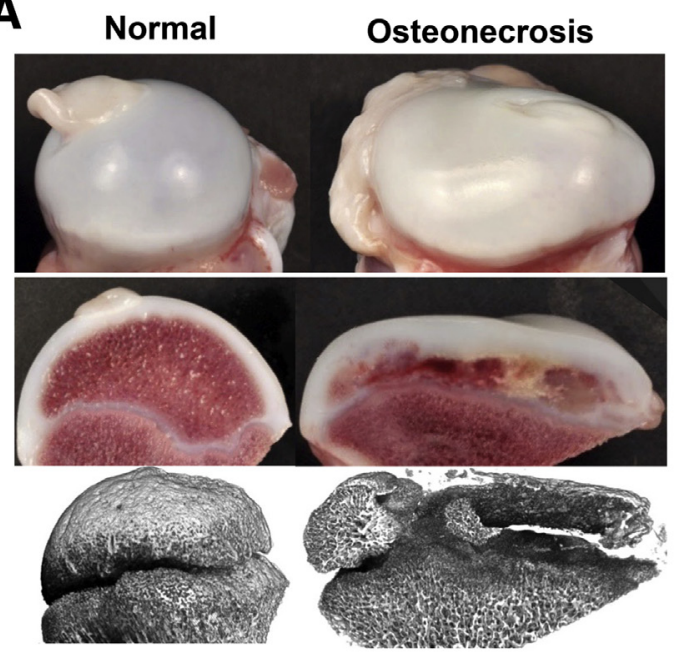

C

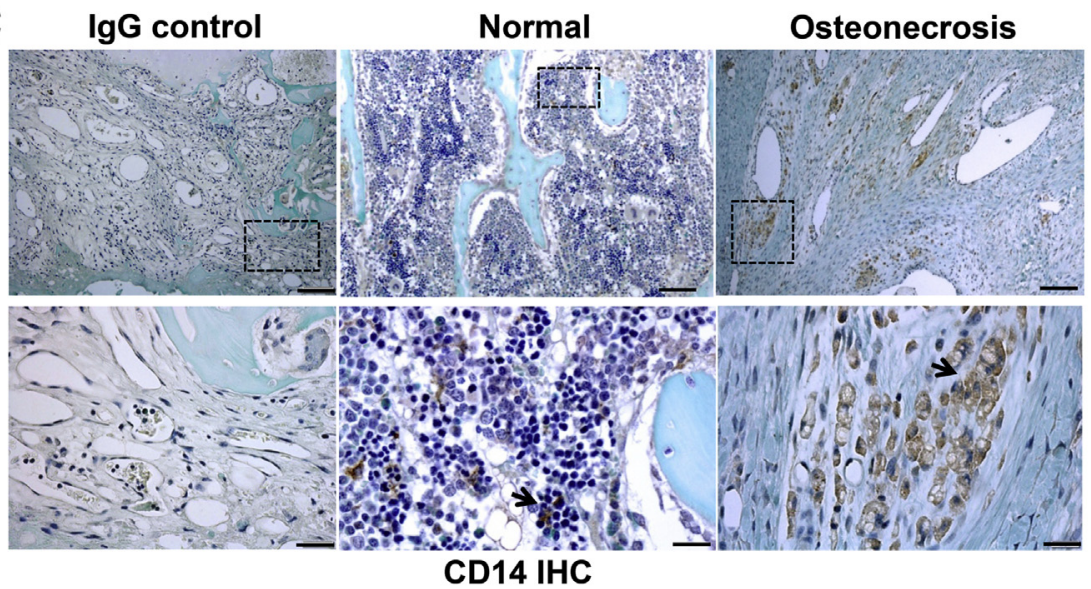

B

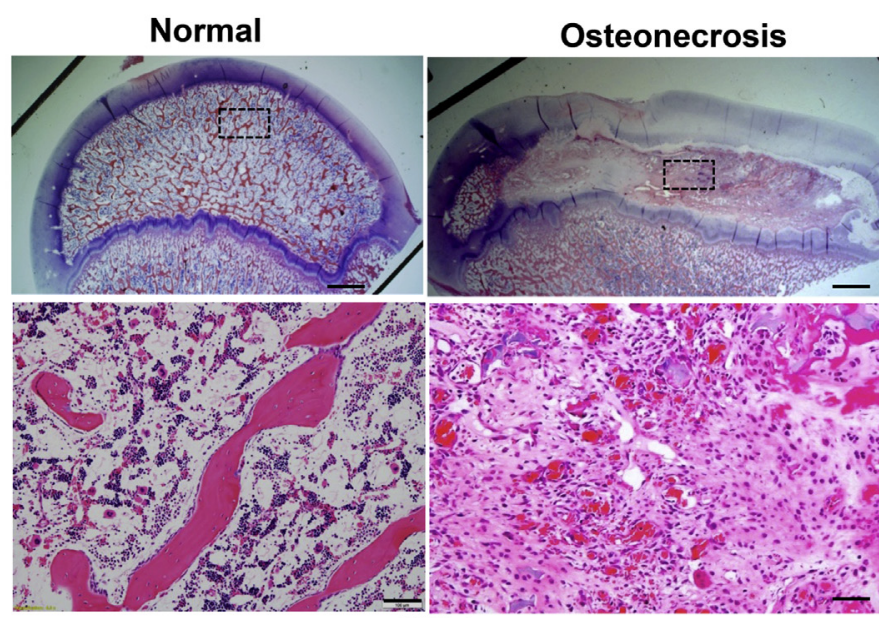

$\mathrm{H} \& \mathrm{E}$

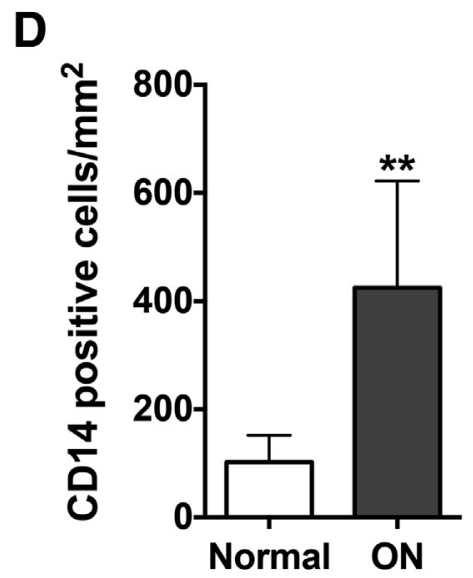

Figure 1 Development of a flattening deformity of the femoral head after ischemic $\mathrm{ON}$ and the presence of macrophages in the fibrovascular repair tissue. A: Appearance of normal and $\mathrm{ON}$ femoral heads at 8 weeks after the induction of ischemia (top row). Gross morphology of the bisected femoral heads (middle row) showing presence of fibrovascular tissue and a three-dimensional micro CT image (bottom row) showing resorption of the bone in some areas of the necrotic femoral head. B: Hematoxylin and eosin staining of the femoral head sections. A fibrovascular repair tissue that contained fragments of necrotic bone was present in the necrotic femoral head. Areas in dashed boxes are shown at higher magnification below. C: CD14 immunohistochemistry followed by fast green and hematoxylin staining showing aggregates of macrophages adjacent to small vessels. Arrows indicates the color of positive staining. Areas in dashed boxes are shown at higher magnification below. $\mathbf{D}$ : Quantitation of $\mathrm{CD} 14^{+}$cells in the perivascular region. Representative images are shown. $n=6$ piglets. Statistical analysis was performed using a Student's $t$-test: ${ }^{* *} P<0.01$. Scale bars: $2 \mathrm{~mm}$ (B, top row); $100 \mu \mathrm{m}$ (B, bottom row, and C, top row); $20 \mu \mathrm{m}$ (C, bottom row). Original magnification: $\times 0.5$ (B, top row); $\times 10$ (B, bottom row); $\times 4$ (C, top row); $\times 40$ (C, bottom row). CT, computed tomography; H\&E, hematoxylin and eosin; IHC, immunohistochemistry; $0 \mathrm{~N}$, osteonecrosis. 
was confirmed by flow cytometry $(P=0.001 ; n=6$ piglets) (Supplemental Figure S3).

To assess the gene expression of M1, M2 markers and inflammatory cytokines, macrophages were captured using NSE-stained frozen sections by LCM (Figure 2, A and B) ( $n=6$ piglets). A quantitative RT-PCR analysis revealed significantly increased mRNA levels (Figure 2C) of proinflammatory M1 macrophage markers (NOS2, IL-12b, Ciita, CD68) in macrophages in the repair tissue, whereas M2 macrophage markers Arg1, Ym1, and CD163 ${ }^{12,17}$ remained unaltered. Furthermore, a significantly increased expression of proinflammatory cytokines (Figure 2D and Supplemental Figure S4) IL-1 $\beta(P<0.0001)$, TNF- $\alpha(P=0.0006)$, and IL-6 $(P=0.04)$ but not IFN- $\gamma$ was observed. The expression levels of anti-inflammatory cytokines IL-4 $(P=0.0003)$ and IL-10 $(P<0.0001)$ were significantly decreased. These results indicate that the repair tissue in the necrotic femoral head contains increased numbers of proinflammatory macrophages.

Sham-operated piglets did not show ischemic osteonecrosis or the presence of fibrovascular tissue (Supplemental Figure S5).

\section{Necrotic Bone Environment Stimulates the Gene Expression of Proinflammatory Cytokines in Macrophages}

To investigate whether necrotic bone environment activates proinflammatory responses in macrophages, bone
A
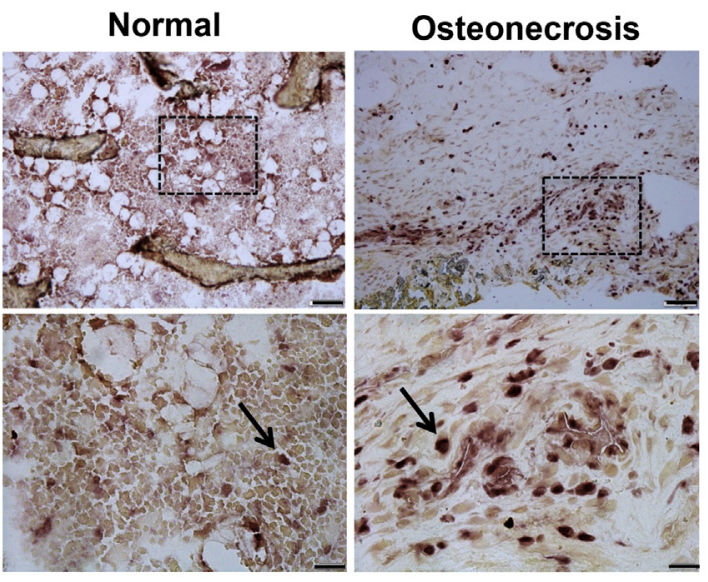

C

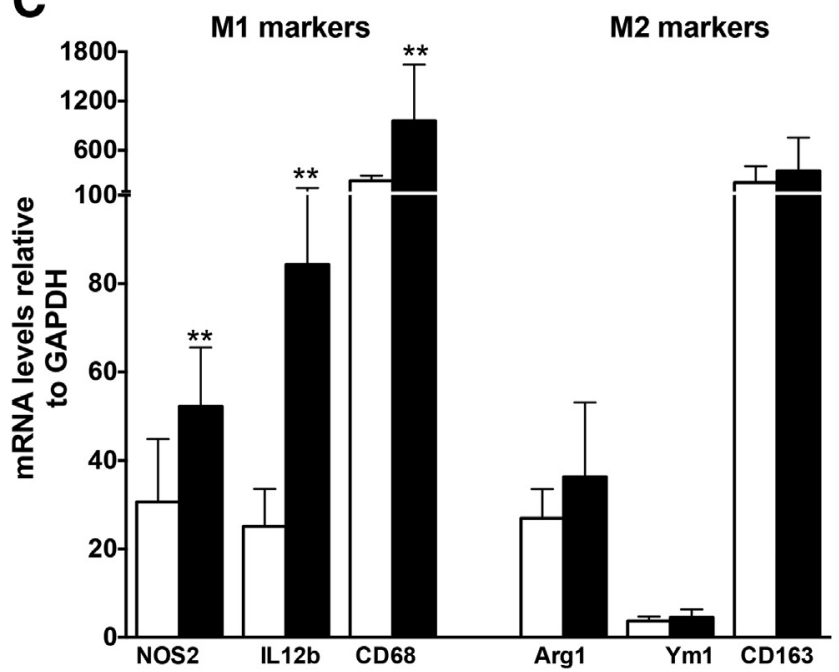

B

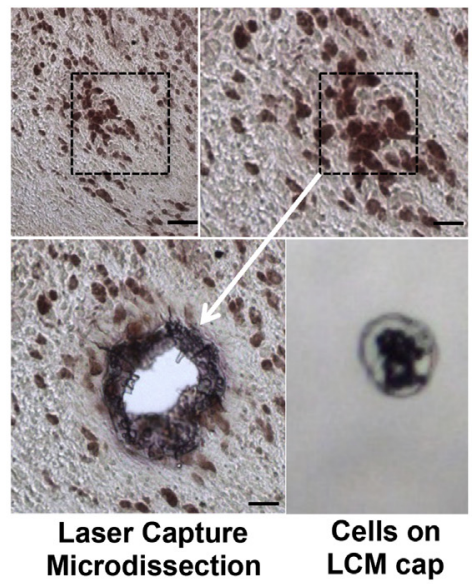

D

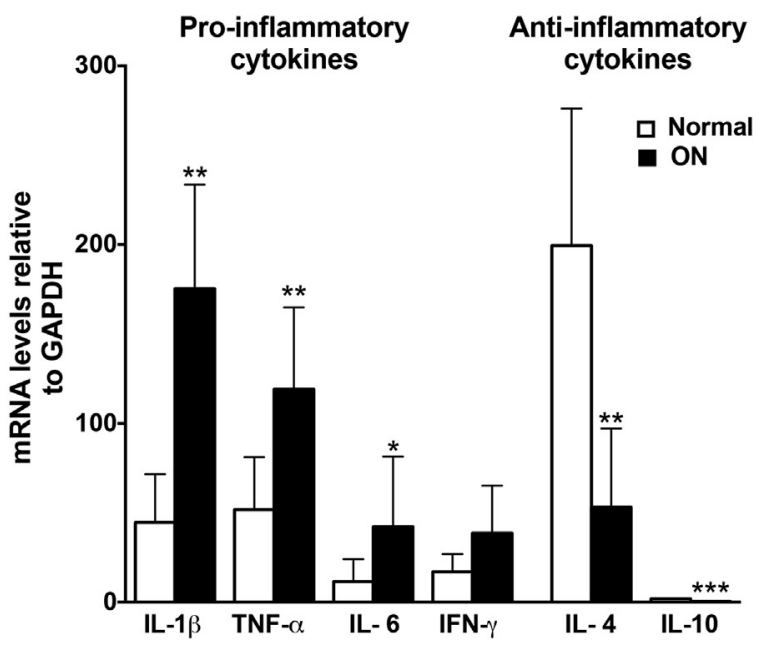

Figure 2 Gene expression levels of M1, M2 markers and cytokines in macrophages after ischemic ON of the femoral head. A: A NSE staining of frozen sections showing the macrophages in the normal bone or necrotic bone repair tissue. Arrows show the typical NSE-positive cells. Areas in dashed boxes are shown at higher magnification below. B: NSE-positive cells were isolated by LCM method. The captured macrophages were collected on the LCM cap, and RNA isolation was performed. Areas in dashed boxes are shown at higher magnification below. C: mRNA levels of markers for M1 and M2 macrophages were assessed by quantitative real-time RT-PCR. D: Levels of gene expression of proinflammatory and anti-inflammatory cytokines in normal and ON samples are shown. Abundance of mRNA levels for the individual genes over GAPDH is shown. $n=6$ piglets for each group. Representative images are shown. Paired $t$-test: ${ }^{*} P<0.05,{ }^{*} P<0.01$, and ${ }^{* *} P<0.001$. Scale bars: $100 \mu \mathrm{m}$ (A, top row); $20 \mu \mathrm{m}$ (A, bottom row, and $\mathbf{B}$, top right panel and bottom row); $50 \mu \mathrm{m}$ (B, top left panel). Original magnification: $\times 4$ (A, top row); $\times 40$ (A, bottom row, and $\mathbf{B}$, top right panel and bottom row); $\times 10$ (B, top left panel). GAPDH, glyceraldehyde-3-phosphate dehydrogenase; NSE; nonspecific esterase; LCM, laser capture microdissection; ON, osteonecrosis. 
marrow-derived macrophages were exposed to the necrotic bone fluid (soluble fraction) or the necrotic bone (sediment fraction) in vitro. The gene expression of proinflammatory cytokine IL-1 $\beta$ was significantly induced by both the necrotic bone fluid and the necrotic bone (Figure 3, A and $\mathrm{C}$ ), whereas the gene expression of TNF- $\alpha$ was stimulated only by necrotic bone (Figure 3, B and D). These results indicate that necrotic bone stimulated the inflammatory cytokine expression from macrophages consistent with the in vivo findings using the LCM method.

To verify whether the increased inflammatory gene expression is specific to the exposure to the necrotic bone, but not to the normal bone, macrophages were exposed to either the normal or the necrotic bone. The gene expression of proinflammatory cytokines IL- $1 \beta$, TNF- $\alpha$, and IL- 6 was significantly increased by the necrotic bone but not by normal bone (Figure 3E), suggesting that necrotic but not normal bone stimulates the expression of proinflammatory cytokines in macrophages.

\section{Necrotic Bone Stimulates the Expression of TLR4 in Macrophages and Activates TLR4 Signaling Pathways}

To determine the molecular mechanisms responsible for the activation of macrophages in the necrotic bone environment, we determined the expression and activation of TLRs on macrophages. The expression levels of TLR4 $(P=0.03$; $n=6$ piglets) were significantly increased in macrophages isolated from the necrotic environment compared with normal bone (Figure 4A) by the LCM method. The increase
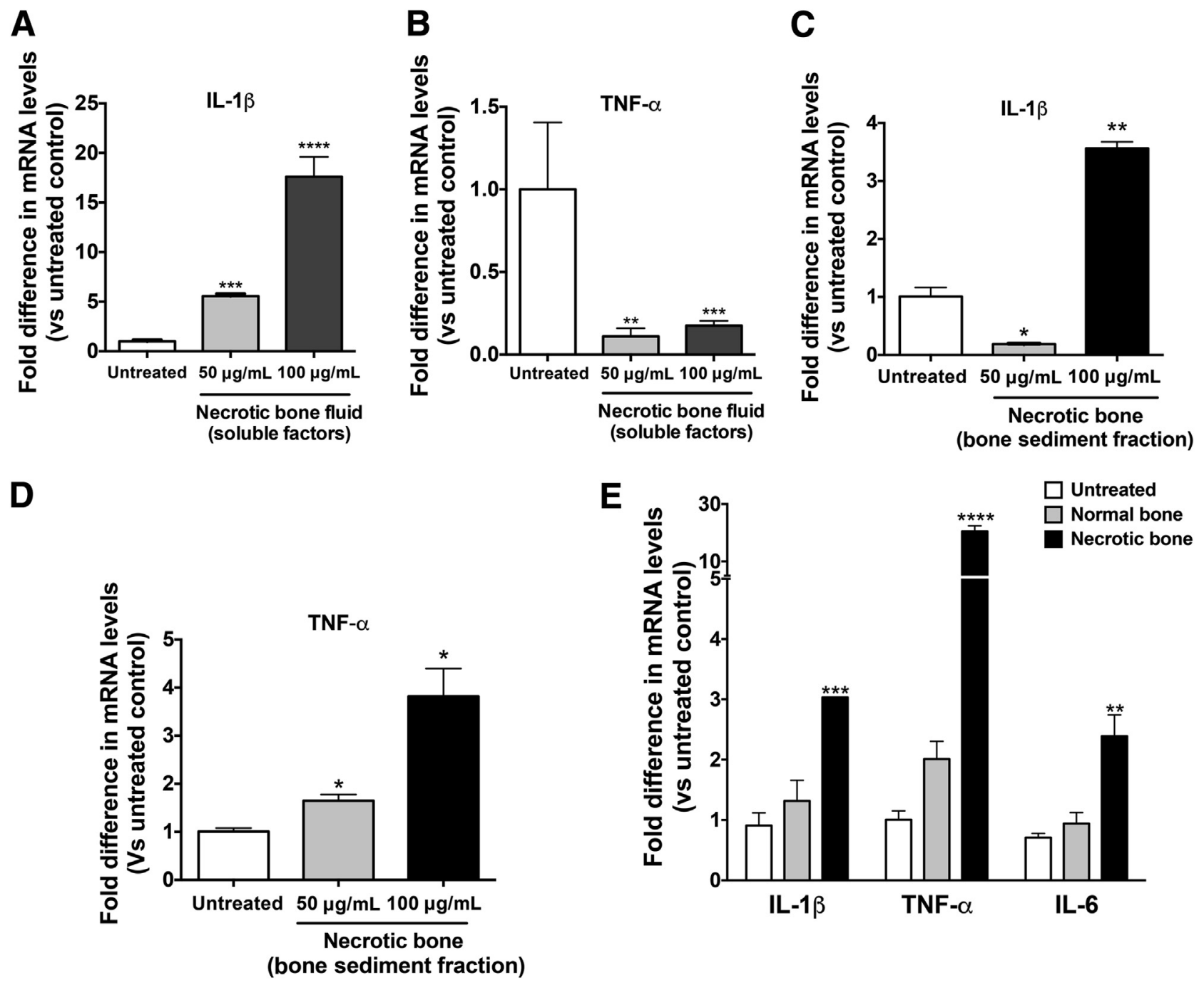

Figure 3 Stimulation of inflammatory cytokine expression in macrophages exposed to the osteonecrosis repair environment. A-D: Macrophages were exposed to the soluble factors in the necrotic bone fluid or the necrotic bone at the indicated concentrations and mRNA levels of proinflammatory cytokines IL$1 \beta$ (A and $\mathbf{C}$ ) and TNF- $\alpha$ (B and $\mathbf{D}$ ) were assessed. The mRNA levels of IL-1 $\beta$ and TNF- $\alpha$ were normalized to GAPDH, and the levels in macrophages exposed to the necrotic environment are shown as fold difference compared with the untreated control. E: The mRNA levels of IL-1 $\beta$, TNF- $\alpha$, and IL- 6 were determined in the macrophages exposed to $100 \mu \mathrm{g} / \mathrm{mL}$ concentration of the normal bone or the necrotic bone. Data normalized to GAPDH mRNA levels are shown as fold difference in treated samples compared with untreated samples. Statistical analysis was performed by analysis of variance and Tukey's post hoc test, ${ }^{*} P<0.05,{ }^{* *} P<0.01,{ }^{* * *} P<0.001$, and ${ }^{* * *} P<0.0001$. A representative of three independent experiments is shown. TNF, tumor necrosis factor. 
in the TLR4 protein expression was evidenced by immunohistochemistry (Figure 4B). The mRNA levels of TLR2 were increased but were not statistically significant $(P=0.46)$. TLR9 expression levels were similar in macrophages in the normal and repair tissue.

In vitro, treatment of macrophages with the necrotic bone but not normal bone resulted in a significant increase in the mRNA and protein levels of TLR4 (Figure 4, C and D). The increased expression of TLR4 on macrophages was confirmed by the double-immunofluorescence method using CD14 antibody and TLR4 antibody (Supplemental Figure S6). These results indicate that necrotic bone stimulates the expression of TLR4 in macrophages.

\section{Necrotic Bone Stimulates Macrophages through the Activation of TLR4}

TLR4 activation stimulates Myd88-dependent ERK1/2 and IKK- $\alpha$ pathways which leads to $\mathrm{NF}-\kappa \mathrm{B}-$ mediated transcription, whereas TRIF-dependent pathway involves IFN- $\gamma$ production and subsequent phosphorylation of STAT1. Treatment of macrophages with necrotic bone stimulated the phosphorylation of ERK1/2 and IKK- $\alpha$ but not STAT1 compared with the normal bone, suggesting a predominant activation of Myd88-dependent TLR4-signaling pathways (Figure 5A). To confirm the role of TLR4, a CRISPR-Cas9 genetic approach was used to ablate TLR4 expression. The activation of ERK1/2, IKK- $\alpha$ but not STAT1, in response to the treatment with necrotic bone was abrogated in macrophages transfected with CRISPR-Cas9 TLR4 plasmid, indicating that TLR4 activation is a major receptor mechanism responsible for necrotic bone-mediated stimulation of macrophages.

Corresponding to TLR4 signaling pathways, the increased gene expression of IL- $1 \beta$, TNF- $\alpha$, and IL- 6 was significantly suppressed in macrophages transfected with CRISPR-Cas9 TLR4 plasmid but not with control plasmid (Figure 5B).

Necrotic Bone Stimulates the Proliferation, Migration, and Proinflammatory Cytokine Responses in Macrophages through the Activation of TLR4

To determine whether activation of TLR4 by necrotic bone is responsible for the stimulation of macrophage inflammatory responses, we treated macrophages with necrotic bone in the presence or absence of the TLR4 inhibitor TAK242. Treatment of macrophages with necrotic bone stimulated the phosphorylation of ERK1/2 and IKK- $\alpha$, suggesting the activation of TLR4-signaling pathways (Figure 6A and Supplemental Figure S7). The activation of ERK1/2 and IKK- $\alpha$ but not STAT1 in response to the treatment with necrotic bone was abrogated in the presence of specific TLR4 inhibitor TAK $242,{ }^{19}$ indicating that TLR4 activation is a major receptor mechanism responsible for necrotic bone-mediated activation of macrophages and that necrotic bone activates TLR4 signaling pathways in
A

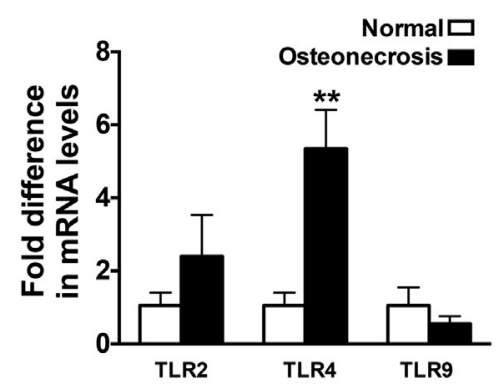

C

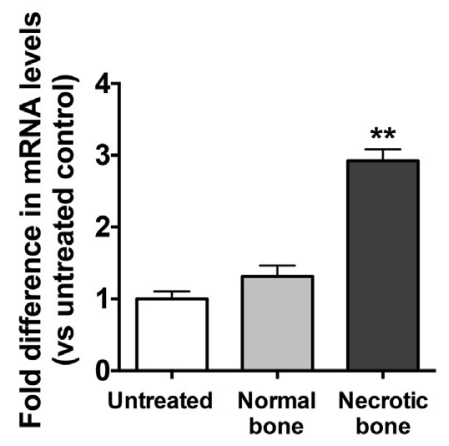

B

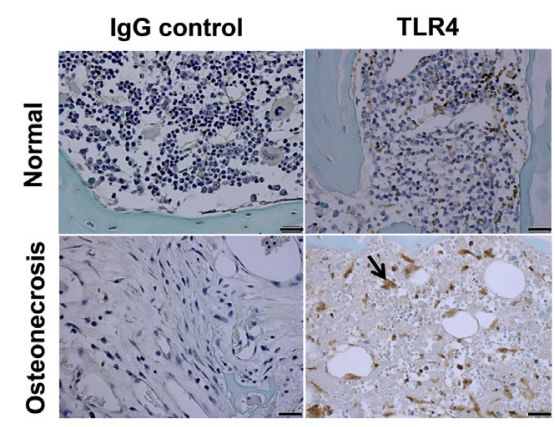

D

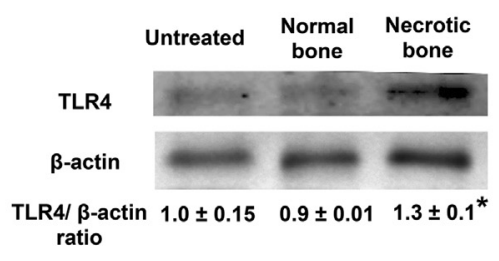

Figure 4 Gene and protein expression levels of TLR4 in macrophages exposed to the necrotic bone. A: Quantitative real-time RT-PCR analysis of mRNA levels of TLRs in the nonspecific esterase-positive cells isolated by the LCM method. The mRNA levels for individual genes were normalized to $\mathrm{GAPDH}$, and fold differences in osteonecrosis were compared with normal. B: Detection of TLR4 protein expression in the cells in normal femoral head or repair tissue of necrotic femoral head by immunohistochemistry. Paraffin sections were stained with IgG control antibody or TLR4 antibody followed by counterstaining with light green and hematoxylin. Arrow indicates the color of positive staining. C: TLR4 gene expression in the macrophages treated with normal bone or necrotic bone was detected by quantitative RT-PCR analysis. The mRNA levels of TLR4 were normalized to GAPDH levels, and the data are shown as a fold-difference compared with untreated control. D: Western blot analysis of TLR4 protein expression in macrophages exposed to 100 $\mathrm{ng} / \mathrm{mL}$ normal or necrotic bone at 24 hours. The blots were probed using anti-TLR4 antibody and $\beta$-actin for loading control. Data are expressed as means \pm SD. $n=6$ piglets for each group (B); $n=3$ blots from independent experiments ( $C$ and D). ${ }^{*} P<0.05$ compared with untreated control, analysis of variance and Tukey's post hoc test ( $t$-test); ${ }^{* *} P<0.01$ compared with untreated control. Scale bars $=20 \mu \mathrm{m}$. Original magnification, $\times 40$. LCM, laser capture microdissection; TLR, Toll-like receptor. 


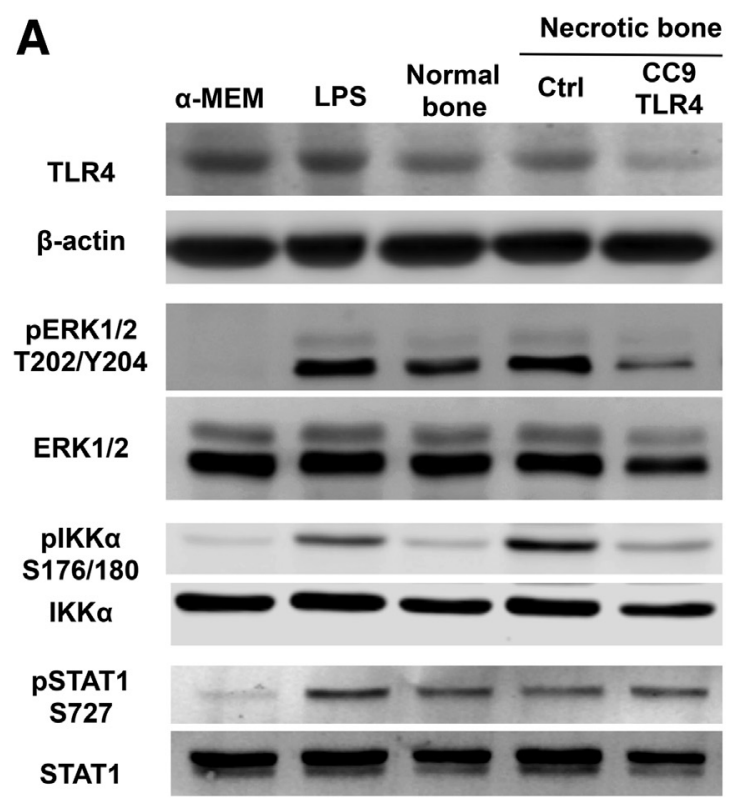

B

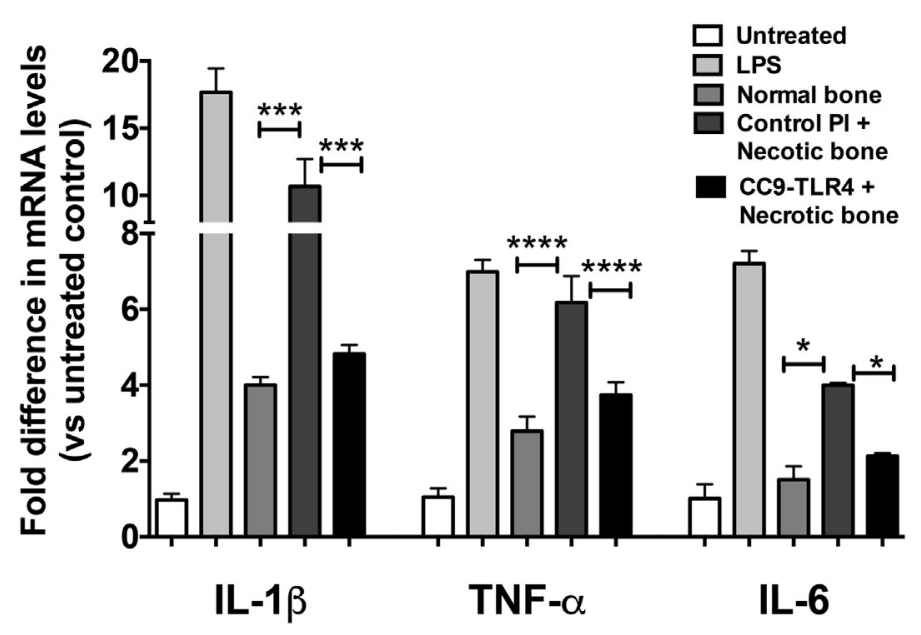

Figure 5 Necrotic bone stimulates macrophages through the activation of TLR4 signaling pathways. A: Western blot analysis of TLR4 activation in macrophages exposed to the necrotic bone. TLR4 gene deletion was performed using the CC9 method. Macrophages were transfected with control plasmid or CC9-TLR4 plasmid. The cells were exposed to normal bone or necrotic bone $(100 \mu \mathrm{g} / \mathrm{mL})$ for 30 minutes. LPS (100 ng/mL) was used as positive control for TLR4 activation. The blots were probed for TLR4 and $\beta$-actin as loading control, phosphorylated forms and total proteins ERK1/2, IKK- $\alpha$, and STAT1. B: The images were captured by LICOR-0dyssey system. mRNA levels of proinflammatory cytokines IL-1 $\beta$, TNF- $\alpha$, and IL- 6 were normalized to GAPDH mRNA levels. Data are shown as the fold difference in treated samples compared with untreated samples. $n=3$ independent representative experiments. ${ }^{\star} P<0.05,{ }^{*} * * P<0.001$, and $* * * * P<0.0001$, analysis of variance and Tukey's post hoc test. CC9, clustered regularly interspaced short palindromic repeats (CRISPR)-CRISPRassociated protein-9 endonuclease (Cas9); Ctrl, control; ERK, extracellular regulated kinase; IKK, Iא kinase; LPS, lipopolysaccharide; MEM, minimum essential medium; Pl, plasmid; TLR, Toll-like receptor; TNF, tumor necrosis factor.

macrophages. Corresponding to TLR4 signaling, TAK242 inhibited IL- $1 \beta$, TNF- $\alpha$, and IL- 6 gene expression in macrophages mediated by necrotic bone (Figure 6B).

We also determined the proliferation and migration responses of macrophages on exposure to necrotic bone. The necrotic bone significantly increased macrophage proliferation (fold-increase: $1.0 \pm 0.2 ; P<0.001$ ) compared with the untreated control and the macrophage-colony stimulating factor control (Figure 6C). The macrophage proliferation stimulated by the necrotic bone was significantly inhibited in the presence of TAK242 (fold-increase: $0.3 \pm 0.08 ; P<0.01)$. Similarly, in the Transwell migration assay (Figure $6 \mathrm{D}$ and Supplemental Figure S8), the addition of necrotic bone significantly increased the migration of macrophages (fold-increase: $6.3 \pm 0.3 ; P<0.0001$ ) compared with the negative control and the macrophage colony-stimulating factor control, which was significantly inhibited (2.2-fold decrease; $P<0.0001)$ in the presence of TAK242 compared with the addition of necrotic bone.

These results indicate that necrotic bone stimulates the proliferation, migration, and proinflammatory cytokine expression of macrophages through TLR4.

\section{Discussion}

The major conclusions of the present study are that ONFH results in the formation of a fibrovascular repair tissue containing increased numbers of proinflammatory macrophages. Necrotic bone stimulates proinflammatory responses from macrophages through the activation of a specific pattern recognition receptor TLR4. We demonstrated that the numbers of proinflammatory M1 macrophages were increased in the repair tissue, which showed increased expression of proinflammatory cytokines IL- $1 \beta$, TNF- $\alpha$, and IL- 6 and the pattern recognition receptor TLR4. Necrotic bone activated the TLR4-signaling pathways in macrophages, and the blockade of TLR4 abrogated macrophage proliferation, migration, and proinflammatory cytokine expression.

The results from this study are consistent with our recent demonstration of the persistence of inflammatory macrophages in the mouse model of ischemic osteonecrosis. ${ }^{20}$ Few studies have previously addressed the role of macrophages in the repair process after ONFH. In patients with $\mathrm{ONFH}^{21}$ and in canine and murine models ${ }^{22}$ of ischemic osteonecrosis, ${ }^{23}$ only the presence of macrophages in the repair tissue has been reported, but the phenotypic characterization of these cells and receptor mechanisms have not been investigated. In bisphosphonate-related osteonecrosis of the jaw and steroid-induced osteonecrosis, which are distinct disorders from ONFH, both the presence of macrophages and the possible association with M1 macrophage activation have been proposed. ${ }^{24,25}$

Our study shows that necrotic bone stimulates inflammatory responses in macrophages through the activation of 
A

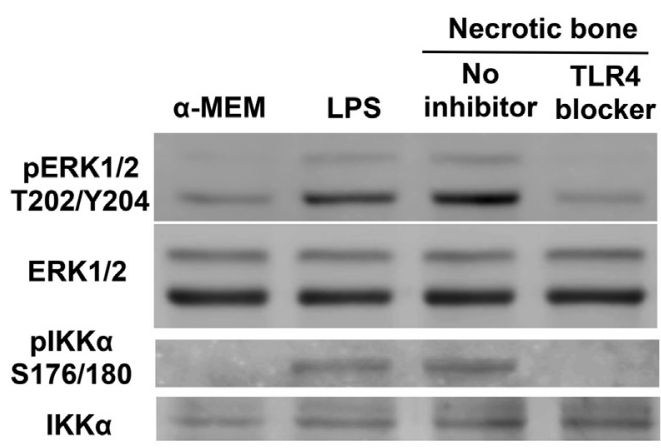

C

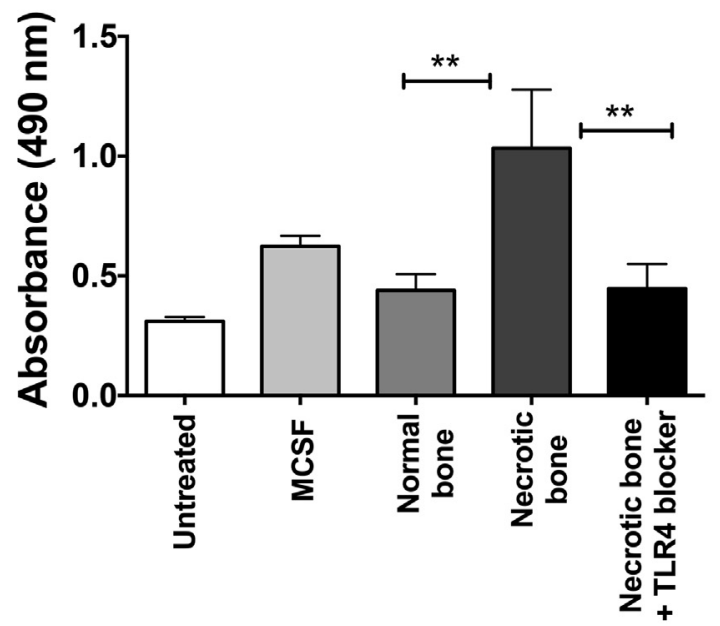

B

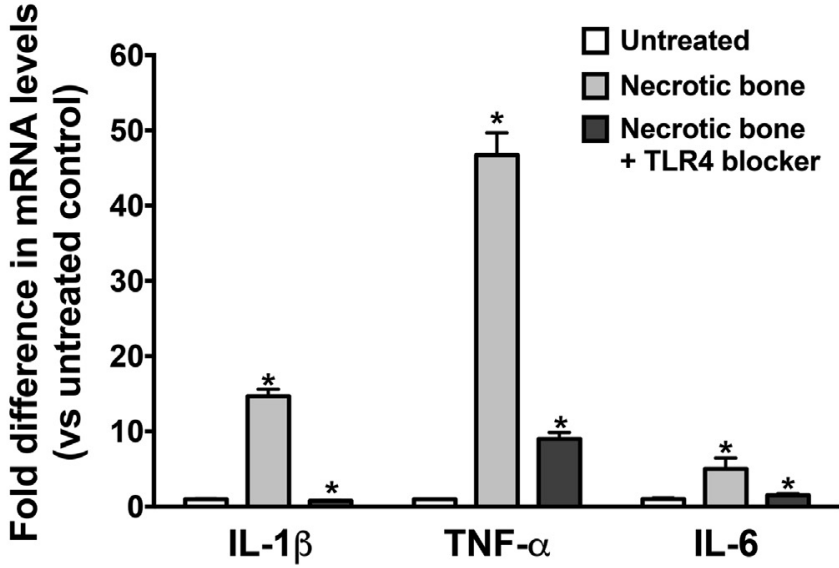

D

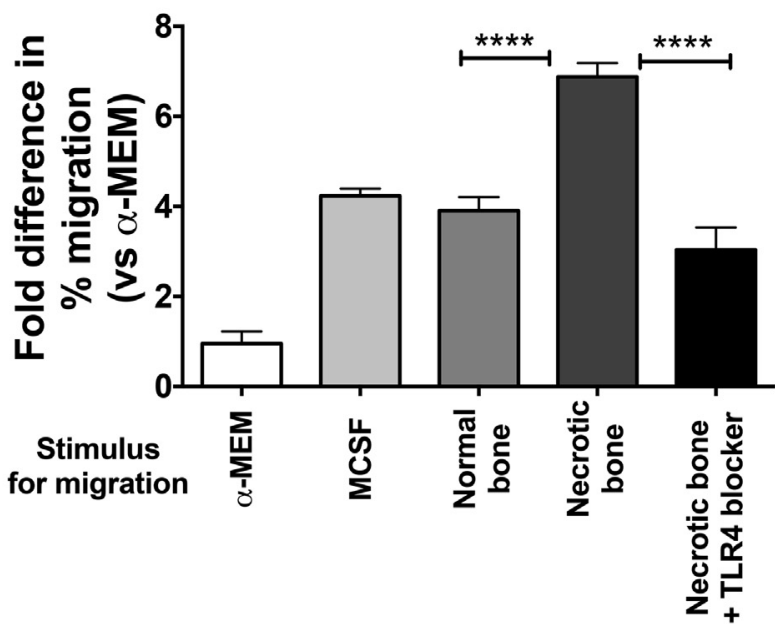

Figure 6 TLR4 inhibition prevents the proinflammatory responses in macrophages induced by necrotic bone. A: Western blot analysis of macrophage activation mediated by the necrotic bone. Macrophages were treated with necrotic bone $(100 \mu \mathrm{g} / \mathrm{mL})$ with or without TLR4 inhibitor TAK242 $(1 \mu \mathrm{mol} / \mathrm{L})$. LPS $(100 \mathrm{ng} / \mathrm{mL})$ was used as positive control for TLR4 activation. The blots were probed for phosphorylated forms and total proteins ERK1/2, IKK- $\alpha$, and the images were captured by LICOR-0dyssey system. B: Macrophages were exposed to the necrotic bone $(100 \mu \mathrm{g} / \mathrm{mL})$ with or without TLR4 inhibitor TAK242 $(1 \mu \mathrm{mol} / \mathrm{L})$, and mRNA levels of proinflammatory cytokines IL-1 $\beta$, TNF- $\alpha$, and IL-6 were normalized to GAPDH mRNA levels. C: Macrophage proliferation in response to treatment with normal or necrotic bone for 48 hours in the presence or absence of TLR4 inhibitor. D: Migration assay, MCSF was used as positive control. Data are expressed as the fold difference in treated samples compared with untreated samples (B). Percentage of migrated cells among total cells is shown as the fold difference compared with the basal migration with no stimulus ( $\alpha$-MEM) (D). $n=3$ independent experiments is shown. ${ }^{*} P<0.05$, ${ }^{* *} P<0.01$, and ${ }^{* * *} P<0.0001$, analysis of variance and Tukey's post hoc test. ERK, extracellular regulated kinase; IKK, IK kinase; LPS, lipopolysaccharide; MCSF, macrophage-colony stimulating factor; MEM, minimum essential medium; TLR, Toll-like receptor; TNF, tumor necrosis factor.

TLR4, suggesting that necrotic bone components are recognized by TLR4. In previous studies in mice, ${ }^{26}$ the injection of normal bone particles resulted in a systemic inflammatory response with an increase in the serum levels of inflammatory cytokines. This elevation in inflammatory cytokine levels was attenuated in TLR4-knockout mice, suggesting a role for TLR4 in recognizing the bone particles. ${ }^{26}$ In our study, the necrotic bone significantly induced macrophage inflammatory responses through TLR4 activation. After ischemic injury, the damaged cell-endogenous and matrix molecules serve as alarmins (or damageassociated molecular patterns, DAMPs) which can recruit and activate macrophages. ${ }^{6-8}$
The activation of macrophages by the necrotic bone suggests that the ischemic injury to bone results in the generation of necrotic bone alarmins, which are recognized by TLR4. Interestingly, in TLR4 signaling after necrotic bone stimulation, Myd88-dependent NF-кB pathway, which includes activation of phospho-ERK, and phospho-IKK- $\alpha$, was stimulated by necrotic bone (Figure 5A) but not TRIF-dependent pathway, which leads to IFN- $\gamma$ production and STAT1 phosphorylation. ${ }^{7}$ The reason for this observation could be that several DAMPs including Tenascin- $\mathrm{C}^{27}$ and biglycans ${ }^{28}$ which are likely to be present in necrotic bone, preferentially activate Myd88-dependent NF- $\kappa$ B (pERK, pIKK- $\alpha$ ) pathway but not TRIF pathway (Figures 5A and 6A) which leads to 
IFN- $\gamma$ production and phosphorylation of STAT $1 .{ }^{7,8}$ In these studies by Midwood et $\mathrm{al}^{27}$ and Schaefer et $\mathrm{al}^{28}$ it was demonstrated that the loss of Myd88 in the cells derived from Myd88 ${ }^{-1-}$ mice abrogated TLR4-dependent responses to Tenascin-c and biglycan.

Another important implication of the absence of STAT1 phosphorylation response to necrotic bone is that the stimulation of TLRs by pathogen-associated molecular patterns from infectious agents and DAMPs (cell-endogenous and matrix components) could be different. Several previous studies, which were reviewed by Piccinini and Midwood ${ }^{8}$ and Schaefer, ${ }^{29}$ suggest that pathogen-associated molecular patterns and DAMPs might elicit different responses while interacting with the same TLRs. ${ }^{30}$ These differences could emanate from ligand recognition and/or signaling mechanisms. In the study by Frey et al, ${ }^{31}$ several proteoglycans (biglycan, decorin, lumican, versican, hyaluronan), which might be present in necrotic bone as DAMPs, were described to mediate inflammatory activation through TLR2/4. Thus, the mechanisms of production of IFN- $\gamma$ downstream of TLRs such as TLR7, TLR8, and TLR9 might be distinct between infections and sterile inflammation, such as after ischemic osteonecrosis. $^{6-10,27-31}$ The possible involvement of alarmins and chronic inflammation was also suggested in osteonecrosis of jaw in a diabetic mouse model, which showed NLRP3/caspase-1-dependent IL-1 $\beta$ production, but the role of TLR4 was not investigated in this study. ${ }^{32}$

In LCPD patients, a recent study evaluated the possible genetic link between TLR4 polymorphisms and the incidence of LCPD, ${ }^{33}$ but no statistically significant association was found. Because of a small sample size and the possibility of type II statistical error, these findings do not exclude the role of TLR4 activation in the pathologic repair process resulting in chronic inflammation. Interestingly, injection of lipopolysaccharide alone, whose inflammatory effects require TLR4 activation, ${ }^{34}$ or in combination with corticosteroids $^{35}$ resulted in ONFH in a rabbit model. These studies further support the pathogenic role of TLR4 activation in osteonecrosis.

The involvement of TLR4 in the stimulation of macrophages by necrotic bone may be therapeutically significant, because TLR4 inhibition is a potential therapeutic strategy to limit inflammatory tissue damage. ${ }^{36}$ In addition, TLR4 activation can result in bone loss due to the effects on the formation of osteoblasts and osteoclasts. The activation of TLR4 signaling pathway inhibits osteoblast differentiation, ${ }^{37}$ whereas TLR4 inhibition decreases osteoclast formation. ${ }^{38}$ Furthermore, TLR4-deficient mice show enhanced bone healing in a calvarial defect model. ${ }^{39}$ Further studies are required to determine the effects of the necrotic bone-mediated macrophage activation on the formation and function of osteoclasts and osteoblasts and whether the blockade of TLR4 (using TLR4 inhibitor, TAK242) might rescue the bone loss and femoral head collapse after ONFH.
Our previous studies showed that the pathologic bone remodeling after ONFH is dominated by the inhibition of new bone formation and excessive bone resorption, ${ }^{13,15}$ which are also characteristic of inflammatory bone loss. ${ }^{40}$ These observations were confirmed by studies in which the new bone formation was promoted by the inhibition of bone resorption and increasing the new bone formation. ${ }^{41-43}$ The formation of a fibrovascular tissue that does not provide mechanical support similar to bone tissue, leads to a mechanical weakening of the femoral head and the development of a flattening deformity. ${ }^{13,15}$ Our results in this study suggest that the pathologic repair process after ONFH may be modulated by macrophages that promote chronic inflammatory responses marked by tissue fibrosis instead of tissue regeneration, that is, new bone formation (Supplemental Figure S9).

This study has some limitations. We examined the involvement of TLRs in ONFH because these receptor mechanisms are known to be crucial in the stimulation of inflammatory responses in macrophages. Among several pattern recognition receptors, only the involvement of TLR2, TLR4, and TLR9 in ONFH were studied. The possible roles of the other pattern recognition receptors (eg, response receptor for advanced glycosylation end products) and the cellular mechanisms (eg, NLRP3 inflammasome) in ONFH requires further investigation. ${ }^{44,45}$ The molecular mechanism by which necrotic bone specifically increased TLR4 expression but not TLR2 or TLR9 needs further evaluation. The in vitro evaluation of the macrophage activation mechanism in response to necrotic bone was studied using chemical inhibitor of TLR4, TAK242, and by genetic ablation of TLR4 in macrophages using CRISPR-Cas9 method. As such, these in vitro assessments limit the ability to conclude a role for this receptor in vivo. For this purpose, future studies will assess the in vivo role of TLR4 activation using the mouse model of ischemic osteonecrosis. ${ }^{20}$ Another limitation of the study is that only an 8-week time point after the induction of ONFH was studied, because this stage of repair corresponds to fibrovascular tissue formation that suggests chronic inflammation. The assessment of macrophage responses at earlier time points is a subject of further studies.

\section{Conclusions}

In conclusion, $\mathrm{ONFH}$ results in the formation of a fibrovascular repair tissue that contains increased numbers of proinflammatory macrophages. Necrotic bone stimulates inflammatory responses in the macrophages through TLR4 activation. Future studies are needed to determine the therapeutic potential of TLR4 blockade to reduce inflammatory damage after ONFH.

\section{Acknowledgments}

We thank Amanda McLerran for animal care and surgical assistance, Reuel Cornelia and Richard Banlaygas for 
assistance with histology, Ila Oxendine and Yang Li for assistance in the in vitro studies.

N.S.A. and H.K.W.K. designed experiments; R.Y. performed the immunofluorescence studies; M.P. did the in vitro quantitative RT-PCR analysis; O.A. performed the microcomputed tomography; N.S.A. and H.K.W.K. reviewed the data; N.S.A., H.K.W.K., and R.Y. wrote the manuscript.

\section{Supplemental Data}

Supplemental material for this article can be found at http://dx.doi:10.1016/j.ajpath.2016.06.024.

\section{References}

1. Catterall A, Pringle J, Byerrs PD, Fulford GE, Kemp HB, Dolman CL, Bell HM, McKibbin B, Rális Z, Jensen OM, Lauritzen J, Ponseti IV, Ogden J: A review of the morphology of Perthes' disease. J Bone Joint Surg Br 1982, 64:269-275

2. Kim HK: Pathophysiology and new strategies for the treatment of Legg-Calvé-Perthes disease. J Bone Joint Surg Am 2012, 94:659-669

3. Kamiya N, Yamaguchi R, Adapala NS, Chen E, Neal D, Jack O, Thoveson A, Gudmundsson P, Brabham C, Aruwajoye O, Drissi H, Kim HK: Legg-Calvé-Perthes disease produces chronic hip synovitis and elevation of interleukin-6 in the synovial fluid. J Bone Miner Res 2015, 30:1009-1013

4. Wynn TA, Barron L: Macrophages: master regulators of inflammation and fibrosis. Semin Liver Dis 2010, 30:245-257

5. Wynn TA, Chawla A, Pollard JW: Macrophage biology in development, homeostasis and disease. Nature 2013, 496:445-455

6. Chen GY, Nunez G: Sterile inflammation: sensing and reacting to damage. Nat Rev Immunol 2010, 10:826-837

7. Takeuchi O, Akira S: Pattern recognition receptors and inflammation. Cell 2010, 140:805-820

8. Piccinini AM, Midwood KS: DAMPening inflammation by modulating TLR signalling. Mediators Inflamm 2010, 2010:672395

9. Kawai T, Akira S: TLR signaling. Cell Death Differ 2006, 13: $816-825$

10. Newton K, Dixit VM: Signaling in innate immunity and inflammation. Cold Spring Harb Perspect Biol 2012, 4:a006049

11. Murray PJ, Wynn TA: Protective and pathogenic functions of macrophage subsets. Nat Rev Immunol 2011, 11:723-737

12. Murray PJ, Allen JE, Biswas SK, Fisher EA, Gilroy DW, Goerdt S, Gordon S, Hamilton JA, Ivashkiv LB, Lawrence T, Locati M, Mantovani A, Martinez FO, Mege JL, Mosser DM, Natoli G, Saeij JP, Schultze JL, Shirey KA, Sica A, Suttles J, Udalova I, van Ginderachter JA, Vogel SN, Wynn TA: Macrophage activation and polarization: nomenclature and experimental guidelines. Immunity 2014, 41:14-20

13. Kim HK, Su PH: Development of flattening and apparent fragmentation following ischemic necrosis of the capital femoral epiphysis in a piglet model. J Bone Joint Surg Am 2002, 84-A:1329-1334

14. Kim HK, Su PH, Qiu YS: Histopathologic changes in growth-plate cartilage following ischemic necrosis of the capital femoral epiphysis. An experimental investigation in immature pigs. J Bone Joint Surg Am 2001, 83-A:688-697

15. Pringle D, Koob TJ, Kim HK: Indentation properties of growing femoral head following ischemic necrosis. J Orthop Res 2004, 22 : $122-130$

16. Horwitz DA, Allison AC, Ward P, Knight N: Identification of human mononuclear leucocyte populations by esterase staining. Clin Exp Immunol 1977, 30:289-298
17. Espina V, WulfKuhle JD, Calvert VS, VanMeter A, Zhou W, Coukos G, Geho DH, Petricoin EF III, Liotta LA: Laser capture microdissection. Nat Protoc 2006, 1:586-603

18. Ezquerra A, Revilla C, Alvarez B, Pérez C, Alonso F, Domínguez J: Porcine myelomonocytic markers and cell populations. Dev Comp Immunol 2009, 33:284-298

19. Kawamoto T, Ii M, Kitazaki T, Lizawa Y, Kimura H: TAK-242 selectively suppresses Toll-like receptor 4-signaling mediated by the intracellular domain. Eur J Pharmacol 2008, 584:40-48

20. Phipps MC, Huang Y, Yamaguchi R, Kamiya N, Adapala NS, Tang L, Kim HK: In vivo monitoring of activated macrophages and neutrophils in response to ischemic osteonecrosis in a mouse model. J Orthop Res 2016, 34:307-313

21. Catto M: Ischaemia of bone. J Clin Pathol Suppl (R Coll Pathol) 1977, 11:78-93

22. Mickelson MR, McCurnin DM, Awbrey BJ, Maynard JA, Martin RK: Legg-Calvé-Perthes disease in dogs: a comparison to human LeggCalvé-Perthes disease. Clin Orthop Relat Res 1981, 157:287-300

23. Bejar J, Misselevich I, Peled E, Zinman C, Reis DN, Boss JH: Pyogenic granuloma-like reaction in the necrotic, vessel-deprived femoral head of the rat. Exp Mol Pathol 2005, 78:140-143

24. Zhang Q, Atsuta I, Liu S, Chen C, Shi S, Shi S, Le AD: IL-17mediated M1/M2 macrophage alteration contributes to pathogenesis of bisphosphonate-related osteonecrosis of the jaws. Clin Cancer Res 2013, 19:3176-3188

25. Wu X, Xu W, Feng X, He Y, Liu X, Gao Y, Yang S, Shao Z, Yang C, Ye Z: TNF-a mediated inflammatory macrophage polarization contributes to the pathogenesis of steroid-induced osteonecrosis in mice. Int J Immunolpathol Pharmacol 2015, 28:351-361

26. Kobbe P, Kaczorowski DJ, Vodovotz Y, Tzioupis CH, Mollen KP, Billiar TR, Pape HC: Local exposure of bone components to injured soft tissue induces Toll-like receptor 4-dependent systemic inflammation with acute lung injury. Shock 2008, 30:686-691

27. Midwood K, Sacre S, Piccinini AM, Inglis J, Trebaul A, Chan E, Drexler S, Sofat N, Kashiwagi M, Orend G, Brennan F, Foxwell B: Tenascin-C is an endogenous activator of Toll-like receptor 4 that is essential for maintaining inflammation in arthritic joint disease. Nat Med 2009, 15:774-780

28. Schaefer L, Babelova A, Kiss E, Hausser HJ, Baliova M, Krzyzankova M, Marsche G, Young MF, Mihalik D, Götte M, Malle E, Schaefer RM, Gröne HJ: The matrix component biglycan is proinflammatory and signals through Toll-like receptors 4 and 2 in macrophages. J Clin Invest 2005, 115:2223-2233

29. Schaefer L: Complexity of danger: the diverse nature of damageassociated molecular patterns. J Biol Chem 2014, 289: 35237-35245

30. Taylor KR, Yamasaki K, Radek KA, Di Nardo A, Goodarzi H, Golenbock D, Beutler B, Gallo RL: Recognition of hyaluronan released in sterile injury involves a unique receptor complex dependent on Tolllike receptor 4, CD44, and MD-2. J Biol Chem 2007, 282: $18265-18275$

31. Frey H, Schroeder N, Manon-Jensen T, Lozzo RV, Schaefer L: Biological interplay between proteoglycans and their innate immune receptors in inflammation. FEBS J 2013, 280:2165-2179

32. Zhang Q, Yu W, Lee S, Xu Q, Naji A, Le AD: Bisphosphonate induces osteonecrosis of jaw in diabetic mice via NLRP3/caspase-1-dependent IL-1beta mechanism. J Bone Miner Res 2015, 30:2300-2312

33. Srzentic S, Spasovski V, Spasovski D, Zivković Z, Matanović D, Bascarević Z, Supić ZT, Stojilijković M, Karan-Djurasević T, Stanković B, Pavlović S, Nikcević G, Vukasinović Z: Association of gene variants in TLR4 and IL-6 genes with Perthes disease. Srp Arh Celok Lek 2014, 142:450-456

34. Irisa $\mathrm{T}$, Yamamoto $\mathrm{T}$, Miyanishi $\mathrm{K}$, Yamashita $\mathrm{A}$, Iwamoto $\mathrm{Y}$, Sugioka Y, Sueishi K: Osteonecrosis induced by a single administration of low-dose lipopolysaccharide in rabbits. Bone 2001, 28:641-649

35. Tian L, Wen Q, Dang X, You W, Fan L, Wang K: Immune response associated with Toll-like receptor 4 signaling pathway leads 
to steroid-induced femoral head osteonecrosis. BMC Musculoskelet Disord 2014, 15:18

36. Hennessy EJ, Parker AE, O'Neill LA: Targeting Toll-like receptors: emerging therapeutics? Nat Rev Drug Discov 2010, 9: 293-307

37. Bandow K, Maeda A, Kakimoto K, Kusuyama J, Shamoto M, Ohnishi T, Matsuguchi T: Molecular mechanisms of the inhibitory effect of lipopolysaccharide (LPS) on osteoblast differentiation. Biochem Biophys Res Commun 2010, 402:755-761

38. Nakamura H, Fukusaki Y, Yoshimura A, Shiraishi C, Kishimoto M, Kaneko T, Hara Y: Lack of Toll-like receptor 4 decreases lipopolysaccharide-induced bone resorption in $\mathrm{C} 3 \mathrm{H} / \mathrm{HeJ}$ mice in vivo. Oral Microbiol Immunol 2008, 23:190-195

39. Wang D, Gilbert JR, Cray JJ Jr, Kubala AA, Shaw MA, Billiar TR, Cooper GM: Accelerated calvarial healing in mice lacking Toll-like receptor 4. PLoS One 2012, 7:e46945

40. Redlich K, Smolen JS: Inflammatory bone loss: pathogenesis and therapeutic intervention. Nat Rev Drug Discov 2012, 11: $234-250$
41. Kim HK, Morgan-Bagley S, Kostenuik P: RANKL inhibition: a novel strategy to decrease femoral head deformity after ischemic osteonecrosis. J Bone Miner Res 2006, 21:1946-1954

42. Kim HK, Randall TS, Bian H, Jenkins J, Garces A, Bauss F: Ibandronate for prevention of femoral head deformity after ischemic necrosis of the capital femoral epiphysis in immature pigs. J Bone Joint Surg Am 2005, 87:550-557

43. Kim HK, Aruwajoye O, Du J, Kamiya N: Local administration of bone morphogenetic protein-2 and bisphosphonate during non-weightbearing treatment of ischemic osteonecrosis of the femoral head: an experimental investigation in immature pigs. J Bone Joint Surg Am 2014, 96:1515-1524

44. Zhou Z, Xiong WC: RAGE and its ligands in bone metabolism. Front Biosci (Schol Ed) 2011, 3:768-776

45. Qu C, Bonar SL, Hickman-Brecks CL, Abu-Amer S, McGeough MD, Pena CA, Broderick L, Yang C, Grimston SK, Kading J, Abu-Amer Y, Novack DV, Hoffman HM, Civitelli R, Mbalaviele G: NLRP3 mediates osteolysis through inflammation-dependent and -independent mechanisms. FASEB J 2015, 29:1269-1279 